\title{
Non-motor symptoms in newly diagnosed Parkinson's disease patients
}

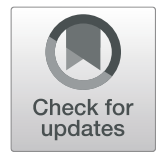

\author{
Osama A. Ragab ${ }^{*}$ D, Yasser A. Elheneedy and Wafik S. Bahnasy
}

\begin{abstract}
Introduction: The non-motor symptoms (NMSs) in Parkinson's disease (PD) patients have greater effects on their quality of life compared to the motor symptoms; however, they are under-recognized.

The aim: The study aims to evaluate the prevalence and severity of NMS in newly diagnosed PD patients in Tanta University hospitals.

Patients and methods: The study included 41 newly diagnosed PD patients. All patients were screened for NMS by the non-motor symptoms questionnaire (NMS-Quest). According to the NMS-Quest response, patients were further evaluated by Sialorrhea Clinical Scale for PD (SCS-PD), Scales for Outcomes in Parkinson's disease for Autonomic symptoms (SCOPA-AUT), Rome III Questionnaire, Nocturnal voiding and Sleep-Interruptions Questionnaire, Brief Pain Inventory, Montreal Cognitive Assessment (MoCA), Scale for Evaluation of Neuropsychiatric Disorders in Parkinson's Disease (SEND-PD), Pittsburgh Sleep Quality Index (PSQI), and questionnaires based upon the International Restless Legs Study Group criteria.

The results: The study included 22 female and 19 male patients; the duration of illness was $2.7 \pm 2.08$ years. Constipation was the most common symptoms as it was present in $73.1 \%$ in the studied patients; $61 \%$ suffered loss of sexual interest. $47.5 \%$ of patients had depressive symptoms. Sleep disturbance was present in $36.6 \%$ of the patients. Anxiety was reported by $30 \%$ of the patients.

Conclusion: All newly diagnosed PD patients suffered one or more NMSs; constipation was the most frequent followed by sexual dysfunction, depressive symptoms, and sleep disturbance, while pain, sialorrhea, and restless leg were the least reported.
\end{abstract}

Keywords: Non-motor symptoms, Parkinson's disease, Drug naïve

\section{Introduction}

Parkinson's disease (PD) is the most common cause of Parkinsonism and is expected to affect about nine million patients by the year 2030 [1]. In a previous Egyptian study, the crude prevalence rate of PD was $548 / 10^{5}$ inhabitants of the studied population [2].

Patients with PD experience a wide range of non-motor symptoms (NMSs) which manifest as cognitive, neuropsychiatric, autonomic, and sensory disturbances; they worsen with disease progression and represent the major determinants of their independency loss [3]. NMSs were present in $96.4 \%$ of the studied patients by Khedr et al. [4] with mood and cognitive dysfunction as the most common followed by sleep disturbance and fatigue. In another

\footnotetext{
* Correspondence: osama.ragab@med.tanta.edu.eg

Neurology Department, Tanta University, Tanta 31527, Egypt
}

Egyptian study by Shalash et al. [5], all studied patients had one or more NMSs, with the most common were fatigue and sleep disturbance.

However, anosmia, sleep disturbance, gastrointestinal function, and mood changes may precede the onset of motor manifestation of PD by 5 or more years [6]. They are not identified by neurologists in over $50 \%$ of consultations, and sleep disturbance is not recognized in over $40 \%$ of PD patients. Drug-naive PD patients are an ideal population to study the differences in presentation of NMS [7].

\section{Aim of the work}

This study aimed to evaluate the prevalence and severity of non-motor symptoms in newly diagnosed (drug naïve) Parkinson's disease patients in Tanta University hospitals. 


\section{Patients and methods}

This study was conducted on all newly diagnosed PD patients referred to outpatient neurology clinics, Department of Neuropsychiatry, Tanta University Hospitals, over a 6-month period from the first of December 2016 to the end of May 2017. Patients were diagnosed according to the United Kingdom Parkinson's Disease Society Brain Bank (UK PDS Brain Bank diagnostic criteria) [8], and stages of Parkinson's disease were assessed using the Hoehn and Yahr scale [9]. Recruited patients were classified either tremor or akinetic rigid predominant type of PD by diving the mean score of tremor items on the mean score of akinetic rigid items (T/AR ratio) of the unified Parkinson's disease rating scale (UPDRS). If the ratio score was more than 0.9 , the patient was considered tremor predominant, while if the score was less than that, the patient was classified as rigid-predominant PD [10].

Patients with PD plus secondary Parkinsonism or patients on L-DOPA treatment were excluded from this study. Also patients with other chronic comorbidities (renal, hepatic, and endocrinal disturbance and chronic chest disease) were excluded.

All PD patients were subjected to the following: full medical history including current and relevant past medications, general and neurological examination, laboratory studies including renal function test, serum electrolytes, liver function test and thyroid hormonal profile, and neuroimaging studies either CT and/or MRI brain if needed. All participants were screened for NMS by the NMS-Quest [11].

Drooling was evaluated using the Sialorrhea Clinical Scale for PD (SCS-PD) [12] and the Scales for Outcomes in Parkinson's disease for Autonomic symptoms (SCOPA-AUT) [13]. Olfaction was evaluated during the clinical interview by assessment of the olfactory nerve. Gastrointestinal and urinary symptoms were evaluated using the Rome III Questionnaire [14] and the SCOPA-AUT [13].

Nocturia was assessed by the Nocturnal voiding and Sleep-Interruptions Questionnaire [15]. Pain was evaluated by the Brief Pain Inventory [16].

Memory and concentration were evaluated using the Montreal Cognitive Assessment (MoCA) [17]. Psychiatric and mood symptoms were evaluated by the Scale for Evaluation of Neuropsychiatric Disorders in Parkinson's Disease (SEND-PD) [18]. Sexual functions were evaluated using SCOPA-AUT [13]. Orthostatic intolerance was evaluated by the SCOPA-AUT and assessment of blood pressure lying at 1-min standing (a cutoff of > $10 \mathrm{mmHg}$ will be considered as indicating potential orthostatic hypotension).

Sleep disturbance was evaluated by the Pittsburgh Sleep Quality Index (PSQI) [19]. Restless leg syndrome was evaluated by screening questionnaires based upon the International Restless Legs Study Group criteria [20].
A signed informed consent was obtained from all participants and their first-degree relatives. The study protocol was approved by the ethical committee in Tanta University, Egypt, under the code number 31,277/12/16 on December 2016.

\section{Statistical analysis}

The collected data were organized, tabulated, and statistically analyzed using SPSS software statistical computer package version 16. For quantitative data, the range in addition to mean and standard deviation was calculated, and the Pearson correlation equation was used. Significance was adopted at $p<0.05$ for interpretation of results of tests of significance.

\section{Results}

The study included 41 newly diagnosed PD patients; all of them were drug naïve. They were 22 females and 19 males with mean age $57.95 \pm 11.94$ years, while the duration of illness was $2.7 \pm 2.08$ years. According to Hoehn and Yahr PD stages, 21 patients were in stage 1, 11 patients in stage 2 , and 9 patients in stage 3 . The mean and standard deviation of UPDRS part $\amalg$ score of studied patients were $35.6 \pm 20.15$. Twenty-three patients were akinetic rigid type and their $\mathrm{T} / \mathrm{AR}$ ratio was $0.74 \pm 0.09$, while the other 18 patients were tremor-predominant $\mathrm{PD}$ type and T/AR ratio was $1.16 \pm 0.21$.

Screening of non-motor symptoms in the studied patients by the non-motor symptoms questionnaire (NMS-Quest) is revealed (Table 1).

A cognitive decline was present in 11 patients who were assessed by both MoCA and MoCA-B test (for illiterate patients); their scores ranged between 16 and 23 , and it showed a significant inverse correlation between the scores and both of the age and duration of illness as $p<0.05$ (Table 2).

Sixteen patients had sleep disturbance; they were evaluated by PSQI; the global score ranged between 7 and 13; and there was a significant direct correlation between the PSQI score and only the age and the presence of tremors as a predominant symptom $(p<0.05)$ (Table 2$)$.

Psychiatric symptoms (psychotic $=11$, mood and anxiety $=27$ ) were assessed by SEND-PD; our results showed that there was a significant direct correlation between both psychotic and mood and anxiety symptoms of the SEND-PD scale and only Hoehn and Yahr stage of disease and duration of illness $(p<0.05)$ (Fig. 1).

Fifteen patients had urinary complaints assessed by the Questionnaire for Evaluating nocturia, nocturnal Enuresis, and Sleep Interruptions; there was an inverse significant correlation between the test score and rigidity as a predominant motor manifestation $(p<0.05)$ (Fig. 2).

Fourteen males and 19 females were evaluated by the SCOPA-AUT questionnaire for evaluating different 
Table 1 Non-motor symptoms in the studied patients by NMS-Quest

\begin{tabular}{|c|c|c|}
\hline & Yes & No \\
\hline Dribbling of saliva during the daytime & $2(4.9 \%)$ & $39(95.1 \%)$ \\
\hline Loss or change in your ability to taste or smell & $4(9.7 \%)$ & $37(90.3 \%)$ \\
\hline Difficulty swallowing food or drinking or problems with choking & 0 & $41(100 \%)$ \\
\hline Vomiting or feelings of sickness (nausea) & $4(9.7 \%)$ & $37(90.3 \%)$ \\
\hline Constipation (less than three bowel movements a week) or having to strain to pass a stool & $30(73.1 \%)$ & $11(26.9 \%)$ \\
\hline Bowel (fecal) incontinence & 0 & $41(100 \%)$ \\
\hline Feeling that your bowel emptying is incomplete after having been to the toilet & $9(21.9 \%)$ & $32(78.1 \%)$ \\
\hline A sense of urgency to pass urine makes you rush to the toilet & $11(26.9 \%)$ & $30(73.1 \%)$ \\
\hline Getting up regularly at night to pass urine & $15(36.6 \%)$ & $26(63.4 \%)$ \\
\hline Unexplained pains (not due to known conditions such as arthritis) & $2(4.9 \%)$ & $38(95.1 \%)$ \\
\hline Unexplained change in weight (not due to change in diet) & 0 & $41(100 \%)$ \\
\hline Problems remembering things that have happened recently or forgetting to do things & $11(26.9 \%)$ & $30(73.1 \%)$ \\
\hline Loss of interest in what is happening around you or in doing things & $19(47.5 \%)$ & $22(53.6 \%)$ \\
\hline Seeing or hearing things you know or are told they are not there & $11(26.9 \%)$ & $30(73.1 \%)$ \\
\hline Difficulty concentrating or staying focused & $9(21.9 \%)$ & $32(78.1 \%)$ \\
\hline Feeling sad, "low," or "blue" & $19(47.5 \%)$ & $22(53.6 \%)$ \\
\hline Feeling anxious, frightened, or panicky & $13(31.7 \%)$ & $28(68.3 \%)$ \\
\hline Feeling less interested in sex or more interested in sex & $25(61 \%)$ & $16(39 \%)$ \\
\hline Finding it difficult to have sex when you try & $19(47.5 \%)$ & $22(53.6 \%)$ \\
\hline Feeling light-headed, dizzy, or weak standing from sitting or lying & $6(14.6 \%)$ & $35(85.4 \%)$ \\
\hline Falling & 0 & $41(100 \%)$ \\
\hline Finding it difficult to stay awake during activities such as working, driving, or eating & $2(4.9 \%)$ & $39(95.1 \%)$ \\
\hline Difficulty getting to sleep at night or staying asleep at night & $14(34.1 \%)$ & $27(65.9 \%)$ \\
\hline Intense, vivid, or frightening dreams & $9(21.9 \%)$ & $22(55 \%)$ \\
\hline Talking or moving about in your sleep, as if you are "acting out" a dream & 0 & $41(100 \%)$ \\
\hline Unpleasant sensations in your legs at night or while resting, and a feeling that you need to move & $2(4.9 \%)$ & $39(95.1 \%)$ \\
\hline Swelling of the legs & 0 & $41(100 \%)$ \\
\hline Excessive sweating & 0 & $41(100 \%)$ \\
\hline Double vision & 0 & $41(100 \%)$ \\
\hline Believing things are happening to you that other people say they are not & $11(26.9 \%)$ & $30(73.1 \%)$ \\
\hline
\end{tabular}

Table 2 Correlation between MoCA test, sleep quality assessment (PSQI), SCOPA-AUT, Rome III adult questionnaire, and demographic data; predominant motor symptoms; Hoehn and Yahr; and duration of illness

\begin{tabular}{|c|c|c|c|c|c|c|c|c|c|c|c|}
\hline \multicolumn{2}{|l|}{ Tremor } & \multicolumn{2}{|c|}{ Rigidity } & \multicolumn{2}{|c|}{ Hoehn and Yahr stage } & \multicolumn{2}{|c|}{ Gender } & \multicolumn{2}{|l|}{ Age } & \multicolumn{2}{|c|}{ Duration of illness } \\
\hline$r$ & $P$ & $r$ & $P$ & $r$ & $P$ & $r$ & $P$ & $r$ & $P$ & $r$ & $P$ \\
\hline \multicolumn{12}{|c|}{ MoCA (+ B) test } \\
\hline 0.45 & 0.18 & -0.26 & 0.45 & -0.17 & 0.63 & 0.3 & 0.31 & -0.78 & $0.006^{*}$ & -0.69 & $0.024^{*}$ \\
\hline \multicolumn{12}{|c|}{ Sleep quality assessment (PSQI) } \\
\hline 0.54 & $0.02^{*}$ & -0.29 & 0.91 & 0.01 & 0.06 & 0.05 & 0.85 & 0.5 & $0.04^{*}$ & 0.34 & 0.18 \\
\hline \multicolumn{12}{|c|}{ SCOPA-AUT } \\
\hline 0.58 & $0.0001^{*}$ & -0.34 & $0.03^{*}$ & 0.57 & $0.002^{*}$ & -0.28 & 0.09 & 0.21 & 0.21 & 0.6 & $<0.0001^{*}$ \\
\hline \multicolumn{12}{|c|}{ Rome III adult questionnaire } \\
\hline 0.06 & 0.73 & 0.09 & 0.6 & 0.11 & 0.54 & 0.19 & 0.28 & 0.03 & 0.82 & 0.29 & 0.17 \\
\hline
\end{tabular}

* statistically significant 

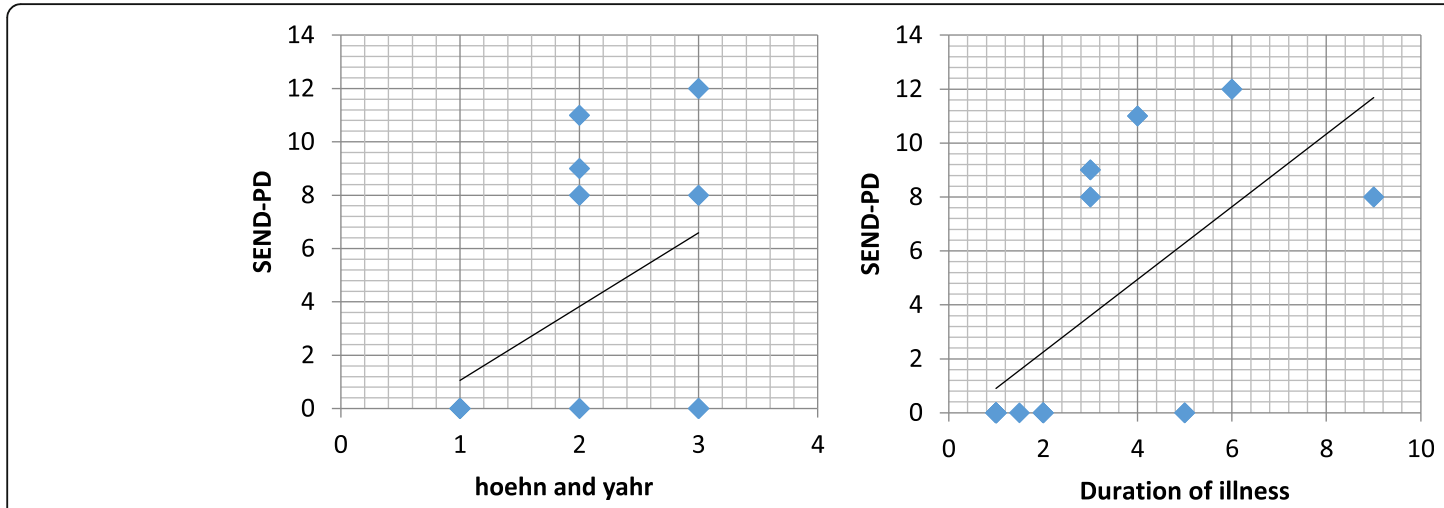

Fig. 1 Correlation between SEND-PD, Hoehn and Yahr stage, and duration of illness

autonomic manifestations including sexual symptoms; our data showed a direct significant correlation between the SCOPA-AUT scores and Hoehn and Yahr stage, duration of illness, and both predominant motor symptoms (tremor and rigidity) $(p<0.05)$ (Table 2).

Gastrointestinal symptoms were present in 32 patients; the most common complaint was constipation while nausea was present in 4 patients. These symptoms were further evaluated by the ROME III adult questionnaire, and the results showed no significant correlation between the ROME III scores and other variables $(p>$ 0.05) (Table 2).

Two patients suffered restless leg syndrome. Their scores on Restless Legs Syndrome Rating Scale were 15 and 17 (moderate severity). Both were females; one of them had tremors as a predominant motor manifestation, while the other had rigidity. Also two patients had dribbling of saliva, and they were evaluated by SCS-PD. They were one male and one female; their scores were 9 and 7 respectively; both tremors and rigidity were clinically evident in both patients. Finally, two female patients reported low back pain which is relieved by NSAIDs.

\section{Discussion}

Non-motor symptoms (NMSs) have long been recognized as an important part of PD, but until recently, they have received relatively little attention. Several studies have shown that many NMSs, particularly depression, are important determinants of health-related quality of life (Hr-QoL) [21]. We conducted this study to explore the prevalence of NMS in PD patients in our local community. For this purpose, we recruited 41 newly diagnosed PD patients; all of them were drug naïve; this was intended to exclude medication side effect and to focus on PD pathology-related non-motor symptoms. One of the surprising results of this study was that $21.9 \%$ of patients were in stage III. We could refer that to the low educational level in rural areas; most patients considered bradykinesia and tremors as part of the physiological process of aging. The second point is that most of the patients who had orthopedic consultation were unfortunately misdiagnosed and treated with neurotonics, so one of the beneficial points of this study is exploring the great need to increase awareness of PD not only for the public but also for physicians especially in the primary care.

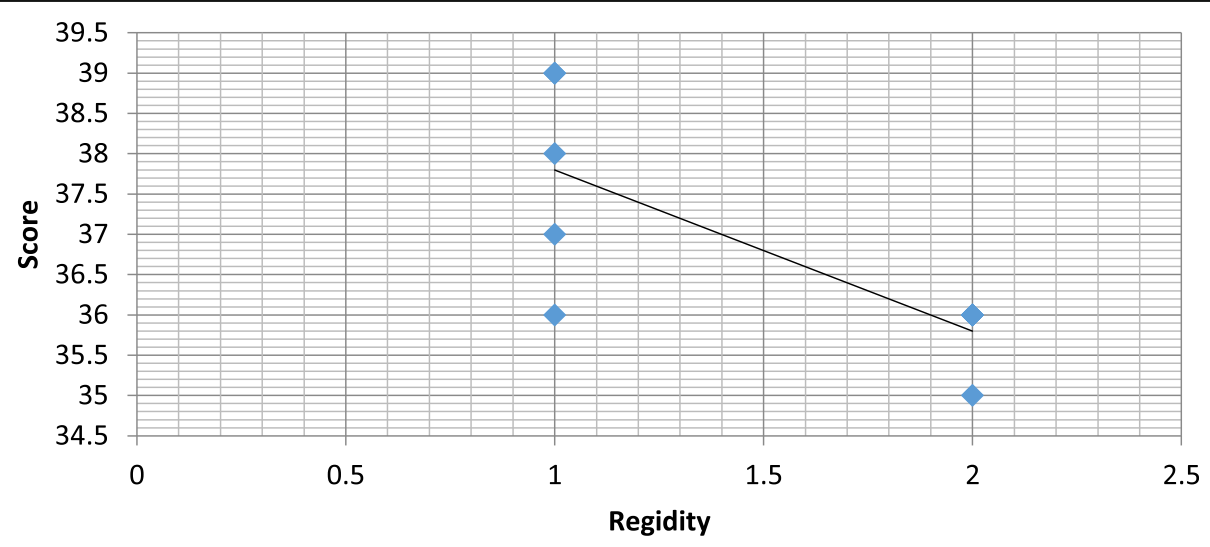

Fig. 2 Correlation between Questionnaire for Evaluating nocturia, nocturnal Enuresis and rigidity 
Screening for NMS in the studied patients by the NMS-Quest [11] (a 30-item self-completed questionnaire featuring responses as "yes," "no," and "do not know" to each item) revealed that constipation was the most common symptoms as it was present in $73.1 \%$ in the studied patients.

An epidemiological study by Abbot et al. [22] revealed an association between the frequency of bowel movements and the risk of developing PD. Also males who have less than one bowel movement daily are at high risk of developing PD than those who had daily bowel movements, and four times higher than those who had two or more bowel movements a day. Several explanations for this finding can be hypothesized. Perhaps constipation is an early manifestation of the disease process itself. Alternatively, rapid transit of material through the gastrointestinal tract reduces exposure to an ingested toxic substance which is active in disease pathogenesis [23]. Our results confirm these hypotheses, revealing the high prevalence of constipation in PD patients. Also Khedr et al. [4] reported the presence of constipation in $51.8 \%$ of PD patients in their study carried out in Upper Egypt.

In our study, there was no significant correlation between these symptoms evaluated by the ROME III adult questionnaire and other variables as $p>0.05$. On the contrary, Pont-Sunyer et al. [24] reported more prevalence of constipation in the rigid type of PD than tremor type; this difference may be related to the different methodology as they recruited medicated patients and higher sample size. Finally, we considered constipation if bowel movements often occur less than usual or consist of hard and dry stools that are painful or difficult to pass, while others restrict diagnosis of constipation if the patient had no bowel movement in 3 days [23].

The second most common symptom in the current study was sexual dysfunction (61\%), which was more common in male patients. Bronner et al. [25] pointed out lower sexual satisfaction in men with PD than in women; this is possibly related to performance problems due to erectile dysfunction with consequent lowered self-esteem. Sexual dysfunction in males with PD typically takes the form of loss of libido, erectile dysfunction, or premature ejaculation; in females, it most often involves low sexual desire and difficulty with arousal and orgasm [26].

Depressive symptoms (47.50\%) followed by anxiety (21.7\%) were common in our patients with less predominant psychotic manifestations (9.7\%). The severity of these symptoms showed a significant correlation with the duration of illness and the stage of disease. Like depression, anxiety may appear at any time during the disease course. It also may precede the appearance of PD motor features [27]. Landau et al. [28] found that the younger the age of onset of PD, the more liability and severity of depression and anxiety; this could be related to the long duration of stress exposure to disease burden.

Urgency and getting up regularly at night to pass urine were present in about one third of our patient cohort. Twenty-five up to fifty percent of PD patients had lower urinary tract symptoms while urodynamic studies documented abnormalities in a much higher percentage [29]. Nocturia is the most commonly reported symptom (57$86 \%)$ followed by increased frequency (32-71\%), urgency (32-68\%), and urge incontinence (21-40\%), and these wide variations reflect differences in patient population, patient medical history, and methods used to ascertain the presence of these symptoms [30].

Nocturnal enuresis and urgency were more common in patients with akinetic rigid than patients with predominant tremor PD. On the other hand, Uchiyama et al. [31] in their 50 early untreated PD patients found no correlation among urinary symptoms, age, sex, or motor symptoms; the mean duration of illness was 23 months, while in our patients, it was 2.78 years. This difference may clarify these conflicting findings.

Sleep disturbance and vivid dreams were present in about one fifth of our PD patients. This seems lower than other literatures which report the prevalence of sleep disturbance in PD from $65 \%$ up to $95 \%$ [32]. It can be explained by the fact that we did not apply a laboratory method (polysomnography), so according to our subjective questionnaires, it is possible to miss mild manifestation. Sleep disturbance was present in $78.6 \%$ of the previous Egyptian study [4] as they recruited both medicated and medicated patients; also the duration of illness was higher in that study. In fact, another study by Prudon et al. [33] reported that newly diagnosed PD patients had minimal differences in subjective or objective sleep disturbance compared to controls; these opposing results necessitate the need for a reliable objective method to evaluate sleep disturbance in drug-naïve PD patients.

Our results showed a direct correlation between the PSQI score and both the patients' age and the presence of tremors as a predominant motor symptom. However, Rolinski et al. [34] reported no correlation between REM behavioral disorders and motor symptoms of PD, as they recruited more than 400 medicated and non-medicated patients.

Cognitive dysfunction including memory disturbance was reported in about $25 \%$ of our patients. We should consider the long duration of illness in our patients which may explain the high percentage of cognitive affection. Going with our finding, Litvan et al. [35] found that $25.8 \%$ of their PD patients were having mild cognitive impairment (MCI). Memory impairment was the most common (13.3\%), followed by visuospatial (11.0\%) and attention/executive ability impairment (10.1\%). MCI was associated with older age at assessment and at disease onset, male gender, depression, more severe motor 
symptoms, and advanced disease stage. Also in the current study, the MoCA test score showed inverse significant correlation with both the age and duration of illness in our study.

Only $15 \%$ of our patients suffered light-headed or weak standing from sitting or lying. In another study, the prevalence of orthostatic hypotension in PD was $30 \%$ [36]. There is a positive significant correlation between orthostatic hypotension and the age of patients, but no correlation neither with sex nor with the motor symptoms in PD as reported by Perez et al. [37] while in our study, the stage of disease and duration of illness were correlated with orthostatic hypotension.

Although olfactory dysfunction is among the earliest non-motor features of PD and is present in approximately $90 \%$ of the early stage of PD cases, it can precede the onset of motor symptoms by years [37]. Only $10 \%$ of our patients reported this symptom. This may be due to our crude method in the assessment of olfaction using coffee and rose water, while in other studies, they usually apply 6 Sniffin' sticks test [38].

The least reported symptoms were restless leg syndrome, drooling of saliva, and unexplained pain. This result confirms the previous study of Verbaan et al. [39] who reported the diagnosis of RLS in 11\% of PD patients. Estimates of the prevalence of drooling in people with PD range from 10 to $84 \%$ with the wide variation in the estimates because of the lack of drooling diagnostic criteria and assessment tools for evaluating its severity [40, 41].

In the study of Ozturk et al. [42], 16.4\% of patients had pain at the time of diagnosis of PD. The sources of pain experienced by patients were $89.0 \%$ musculoskeletal, $31.5 \%$ radicular/peripheral neuropathic, $15.1 \%$ dystonic, and $4.1 \%$ central. This finding is going with our result, as only two patients had mild musculoskeletal pain which is relieved by non-steroidal anti-inflammatory drugs.

Finally, either thermoregulatory dysfunction, fecal incontinence, or dysphagia was reported by our studied patients. Autonomic symptoms such as hyperhidrosis may be associated with variable blood levels of the dopaminergic drugs, but they do not appear to correlate with the duration of the disease as declared by Sveinbjornsdottir [43]. The current studies relate fecal incontinence to abuse of laxative in the management of constipation [44].

\section{Conclusion}

All newly diagnosed PD patients suffered one or more non-motor symptoms, reflecting the great need to incorporate the assessment tools for these symptoms in routine clinical evaluation in PD patients. Gastrointestinal symptoms especially constipation were the most frequent followed by sexual dysfunction, depressive symptoms, and sleep disturbance, while pain, sialorrhea, and restless leg were the least reported by our studied patients.

\section{Study limitations}

There are two limitations in this study: the first one, we had not use a specific scale to assess depression as it may affect the presentation and severity of NMS, and the second, an Arabic validated version of IRLSS to evaluate restless leg syndrome was not applied.

\section{Abbreviations \\ MCl: Mild cognitive impairment; MoCA: Montreal Cognitive Assessment; NMS-Quest: Non-motor symptoms questionnaire; NMSs: Non-motor symptoms; PD: Parkinson disease; PSQI: Pittsburgh Sleep Quality Index; REM: Rapid eye movement; SCOPA-AUT: Scales for Outcomes in Parkinson's disease for Autonomic symptoms; SCS-PD: Sialorrhea Clinical Scale for PD; SEND-PD: Neuropsychiatric Disorders in Parkinson's Disease}

\section{Acknowledgements}

We wish to express our great appreciation to our patients and their family for supporting us during this work. Finally, we should thank Mrs. Hagar Aboelfath Belal for her help in editing this manuscript.

\section{Funding}

This research did not receive any specific grant from funding agencies in the public, commercial, or not-for-profit sectors.

Availability of data and materials

All raw data will be available on the editor request.

\section{Authors' contributions}

All authors have participated in the design of the study, acquisition of the data, data interpretation, and revision of the manuscript. OR recruited the patient and carried out the clinical and neurological evaluation and editing of the manuscript. YE recruited some patients, carried out the clinical and neurological evaluation, and participated in the interpretation of the study results. WB participated in the interpretation of the study results and revision of the manuscript. All authors read and approved the final manuscript.

\section{Ethics approval and consent to participate}

The study protocol was approved by the ethical committee in Tanta University, Egypt, under the code number (31277/12/16) on December 2016. Participation was voluntary and all contributors or their first-degree relatives received detailed information about the aims of this research work and an informed consent was obtained prior to the commencement of the study.

\section{Consent for publication}

A written informed consent for the publication was obtained from all the participants and their first degree relatives.

\section{Competing interests}

The authors declare that they have no competing interests.

\section{Publisher's Note}

Springer Nature remains neutral with regard to jurisdictional claims in published maps and institutional affiliations.

Received: 12 October 2017 Accepted: 28 March 2019

Published online: 16 April 2019

References

1. Lyons KE, Pahwa R. The impact and management of nonmotor symptoms of Parkinson's disease. Am J Manag Care. 2011;17(Suppl 12):S308-14.

2. Khedr EM, Fawi G, Abbas MA, Mohammed TA, El-Fetoh NA, Attar GA, Zaki AF. Prevalence of Parkinsonism and Parkinson's disease in Qena governorate/Egypt: a cross-sectional community-based survey. Neurol Res. 2015;37(7):607-18

3. Coelho M, Ferreira JJ. Non-motor symptoms in advanced Parkinson's disease. Non-motor symptoms of Parkinson's disease; 2014. p. 44

4. Khedr EM, El Fetoh NA, Khalifa H, Ahmed MA, El Beh KM. Prevalence of non motor features in a cohort of Parkinson's disease patients. Clin Neurol Neurosurg. 2013;115(6):673-7. 
5. Shalash AS, Hamid E, Elrassas HH, Bedair AS, Abushouk Al, Khamis M, Hashim M, Ahmed NS, Ashour S, Elbalkimy M. Non-motor symptoms as predictors of quality of life in Egyptian patients with Parkinson's disease: a cross-sectional study using a culturally adapted 39-item Parkinson's disease questionnaire. Front Neurol. 2018;9:357.

6. Goldman JG, Postuma R. Premotor and non-motor features of Parkinson's disease. Curr Opin Neurol. 2014;27(4):434.

7. Zis $P$, Erro R, Walton CC, Sauerbier A, Chaudhuri KR. The range and nature of non-motor symptoms in drug-naive Parkinson's disease patients: a stateof-the-art systematic review. NPJ Park Dis. 2015;1:15013.

8. Hughes AJ, Daniel SE, Kilford L, Lees AJ. Accuracy of clinical diagnosis of idiopathic Parkinson's disease: a clinico-pathological study of 100 cases. J Neurol Neurosurg Psychiatry. 1992;55(3):181-4.

9. Hoehn MM, Yahr MD. Parkinsonism onset, progression, and mortality. Neurology. 1967;17(5):427.

10. Schiess MC, Zheng H, Soukup VM, Bonnen JG, Nauta HJ. Parkinson's disease subtypes: clinical classification and ventricular cerebrospinal fluid analysis. Parkinsonism Relat Disord. 2000;6(2):69-76.

11. Romenets SR, Wolfson C, Galatas C, Pelletier A, Altman R, Wadup L, Postuma RB. Validation of the non-motor symptoms questionnaire (NMS-Quest). Parkinsonism Relat Disord. 2012;18(1):54-8.

12. Perez Lloret S, Pirán Arce G, Rossi M, Caivano Nemet ML, Salsamendi P, Merello M. Validation of a new scale for the evaluation of sialorrhea in patients with Parkinson's disease. Mov Disord. 2007;22(1):107-11.

13. Visser M, Marinus J, Stiggelbout AM, Van Hilten JJ. Assessment of autonomic dysfunction in Parkinson's disease: the SCOPA-AUT. Mov Disord. 2004;19(11): 1306-12.

14. Drossman DA. Introduction. The Rome Foundation and Rome III. Neurogastroenterol Motil. 2007;19(10):783-6.

15. Bing MH, Moller LA, Jennum P, Mortensen S, Lose G. Validity and reliability of a questionnaire for evaluating nocturia, nocturnal enuresis and sleepinterruptions in an elderly population. Eur Urol. 2006;49(4):710-9.

16. Cleeland CS, Ryan KM. Pain assessment: global use of the Brief Pain Inventory. Ann Acad Med Singap. 1994;23(2):129-38.

17. Gill DJ, Freshman A, Blender JA, Ravina B. The Montreal cognitive assessment as a screening tool for cognitive impairment in Parkinson's disease. Mov Disord. 2008;23(7):1043-6.

18. Martinez-Martin P. Frades-Payo B, Agüera-Ortiz L, Ayuga-Martinez A. A short scale for evaluation of neuropsychiatric disorders in Parkinson's disease: first psychometric approach. J Neurol. 2012;259(11):2299-308.

19. Mollayeva T, Thurairajah P, Burton K, Mollayeva S, Shapiro CM, Colantonio A. The Pittsburgh sleep quality index as a screening tool for sleep dysfunction in clinical and non-clinical samples: a systematic review and meta-analysis. Sleep Med Rev. 2016;25:52-73.

20. Allen RP, Picchietti DL, Garcia-Borreguero D, Ondo WG, Walters AS, Winkelman JW, Zucconi M, Ferri R, Trenkwalder C, Lee HB, International Restless Legs Syndrome Study Group. Restless legs syndrome/Willis-Ekbom disease diagnostic criteria: updated International Restless Legs Syndrome Study Group (IRLSSG) consensus criteria-history, rationale, description, and significance. Sleep Med 2014;15(8):860-873.

21. Berganzo K, Tijero B, Gonzalez-Eizaguirre A, Somme J, Lezcano E, Gabilondo I, Fernandez M, Zarranz JJ, Gómez-Esteban JC. Motor and non-motor symptoms of Parkinson's disease and their impact on quality of life and on different clinical subgroups. Neurología (Engl Ed). 2016;31(9):585-91.

22. Abbott RD, Petrovitch $\mathrm{H}$, White LR, et al. Frequency of bowel movements and the future risk of Parkinson's disease. Neurology. 2001;57:456-62.

23. Adams-Carr KL, Bestwick JP, Shribman S, Lees A, Schrag A, Noyce AJ. Constipation preceding Parkinson's disease: a systematic review and metaanalysis. J Neurol Neurosurg Psychiatry. 2016;87(7):710-6.

24. Pont-Sunyer C, Hotter A, Gaig C, Seppi K, Compta Y, Katzenschlager R, Mas N, Hofeneder D, Brücke T, Bayés A, Wenzel K. The onset of nonmotor symptoms in Parkinson's disease (the ONSET PD study). Mov Disord. 2015;30(2):229-37.

25. Bronner G, Cohen OS, Yahalom G, Kozlova E, Orlev Y, Molshatzki N, Strauss $\mathrm{H}$, Hassin-Baer S. Correlates of quality of sexual life in male and female patients with Parkinson's disease and their partners. Parkinsonism Relat Disord. 2014:20(10):1085-8.

26. Ye H, Mao Z, Ji S, Yang Q, Xue Z. Parkinson's disease clinical study of sexual dysfunction. Mov Disord. 2015;30:S190.

27. Broen MP, Narayen NE, Kuijf ML, Dissanayaka NN, Leentjens AF. Prevalence of anxiety in Parkinson's disease: a systematic review and meta-analysis. Mov Disord. 2016;31(8):1125-33.
28. Landau S, Harris V, Burn DJ, Hindle JV, Hurt CS, Samuel M, Wilson KC, Brown RG. Anxiety and anxious-depression in Parkinson's disease over a 4-year period: a latent transition analysis. Psychol Med. 2016;46(3):657-67.

29. Vodušek DB, Boller F. Lower urinary tract dysfunction in patients with Parkinsonism and other neurodegenerative disorders. Neurol Sex Bladder Disord. 2015;130:335

30. McDonald C, Winge K, Burn DJ. Lower urinary tract symptoms in Parkinson's disease: prevalence, aetiology and management. Parkinsonism Relat Disord. 2017;35:8-16.

31. Uchiyama T, Sakakibara R, Yamamoto T, Ito T, Yamaguchi C, Awa Y, Yanagisawa M, Higuchi $Y$, Sato $Y$, Ichikawa T, Yamanishi T. Urinary dysfunction in early and untreated Parkinson's disease. J Neurol Neurosurg Psychiatry. 2011;82(12):1382-6.

32. Madhusudhan D, Sisniega D, Ferree A, Weinberg J, Saint-Hilaire M, Ellias S, Hohler AD. Sleep disturbance in Parkinson's disease varies with age of onset and family history. Adv Park Dis. 2016;5(04):103.

33. Prudon B, Duncan GW, Khoo TK, Yarnall AJ, Burn DJ, Anderson KN. Primary sleep disorder prevalence in patients with newly diagnosed Parkinson's disease. Mov Disord. 2014;29(2):259-62.

34. Rolinski M, Szewczyk-Krolikowski K, Tomlinson PR, Nithi K, Talbot K, BenShlomo Y, Hu MT. REM sleep behaviour disorder is associated with worse quality of life and other non-motor features in early Parkinson's disease. J Neurol Neurosurg Psychiatry. 2014;85(5):560-6.

35. Litvan I, Goldman JG, Tröster Al, Schmand BA, Weintraub D, Petersen RC, Mollenhauer B, Adler CH, Marder K, Williams-Gray CH, Aarsland D. Diagnostic criteria for mild cognitive impairment in Parkinson's disease: Movement Disorder Society Task Force guidelines. Mov Disord. 2012;27(3): 349-56.

36. Lim SY, Tan AH. Management of autonomic dysfunction in Parkinson's disease. Parkinson's disease: current and future therapeutics and clinical trials; 2016. p. 93.

37. Perez-Lloret S, Rey MV, Fabre N, Ory F, Spampinato U, Senard JM, Pavy-Le Traon A, Montastruc JL, Rascol O. Factors related to orthostatic hypotension in Parkinson's disease. Parkinsonism Relat Disord. 2012;18(5):501-5.

38. Casjens S, Eckert A, Woitalla D, Ellrichmann G, Turewicz M, Stephan C, Eisenacher M, May C, Meyer HE, Brüning T, Pesch B. Diagnostic value of the impairment of olfaction in Parkinson's disease. PLoS One. 2013;8(5):e64735.

39. Verbaan D, van Rooden SM, van Hilten JJ, Rijsman RM. Prevalence and clinical profile of restless legs syndrome in Parkinson's disease. Mov Disord. 2010;25(13):2142-7.

40. Srivanitchapoom P, Pandey S, Hallett M. Drooling in Parkinson's disease: a review. Parkinsonism Relat Disord. 2014:20(11):1109-18.

41. Gonzalez-L MD, Martinez C, y Fortuny IB, Suso-Vergara S. Factors in the efficacy, safety, and impact on quality of life for treatment of drooling with botulinum toxin type a in patients with cerebral palsy. Am J Phys Med Rehabil. 2017:96(2):68-76.

42. Ozturk EA, Gundogdu I, Kocer B, Comoglu S, Cakci A. Chronic pain in Parkinson's disease's disease: frequency, characteristics, independent factors, and relationship with health-related quality of life. J Back Musculoskelet Rehabil. 2017:30(1):101-8.

43. Sveinbjornsdottir S. The clinical symptoms of Parkinson's disease. J Neurochem. 2016;139(S1):318-24

44. Serra MC, Landry A, Juncos JL, Markland AD, Burgio KL, Goode PS, Johnson TM, Vaughan CP. Increased odds of bladder and bowel symptoms in early Parkinson's disease. Neurourol Urodyn. 2018:37(4):1344-8. 